Pesq. Vet. Bras. 34(Supl.1):1-6, dezembro 2014 DOI: 10.1590/S0100-736X2014001300001

\title{
Padronização de técnica manual para obtenção de plasma rico em plaquetas de bovino ${ }^{1}$
}

\author{
Ana Paula L. Marques ${ }^{2 *}$, Rita de Cássia C.M. Botteon ${ }^{3}$, Matheus D. Cordeiro ${ }^{4}$, Carlos \\ H. Machado ${ }^{3}$, Paulo de Tarso L. Botteon ${ }^{3}$, Janne P.N. de Barros ${ }^{5}$ e Bruno F. Spíndola ${ }^{5}$
}

\begin{abstract}
Marques A.P.L., Botteon R.C.C.M., Cordeiro M.D., Machado C.H., Botteon P.T.L., Barros J.P.N. \& Spíndola B.F. 2014. [Standardization of manual technique for obtaining platelet-rich plasma in cattle.] Padronização de técnica manual para obtenção de plasma rico em plaquetas de bovino. Pesquisa Veterinária Brasileira 34(Supl.):1-6. Departamento de Medicina e Cirurgia Veterinária, Instituto de Veterinária, Universidade Federal Rural do Rio de Janeiro, Seropédica, RJ 23890-000, Brazil. E-mail: marquesapl@ufrrj.br

For standardization of manual technique to obtain autologous platelet-rich plasma (PRP) in cattle with reduced cost (manual method) and good quality (ability to concentrate platelets, high level of growth factors and reduced contamination with leukocytes and erythrocytes), that may be used as a modulating agent of the immune response of cows chronically infected with various diseases, $450 \mathrm{ml}$ of whole blood from nine clinically and hematologically healthy cattle were collected in CPDA-1 bags and processed within four hours after collection. The blood was divided in aliquots to evaluate 8 protocols (P) of double centrifugation which varied as the speed and time of centrifugation. Platelet, erythrocytes and leukocytes counts in PRP were performed by manual method in a Neubauer chamber. The highest concentration of platelets was obtained in P5 (400g and 800g both for $10 \mathrm{~min}$ ), followed by ( $p>0.05$ ) P3 (120g e 473g ambos durante $10 \mathrm{~min}$ ), P4 (300g e 640g durante 10 min cada), P6 (640g durante $10 \mathrm{~min}$ e $640 \mathrm{~g}$ durante $5 \mathrm{~min}$ ), P8 (640g durante 5 min e $120 \mathrm{~g}$ durante $10 \mathrm{~min})$ and P7 $(720 \mathrm{~g}$ and $720 \mathrm{~g}$ both for $5 \mathrm{~min})$ and different $(\mathrm{p}<0.05)$ than the protocols that had lower rates at P1 (120g to $240 \mathrm{~g}$, both for 5 minutes) and P2 (both $120 \mathrm{~g}$ and 473g for $5 \mathrm{~min}$ ). As for erythrocytes, P8, P7, P6, P5, P4 showed lower concentrations with higher values $(\mathrm{p}<0.05)$ observed in $\mathrm{P} 3$ and $\mathrm{P} 2$. Lesser values of leukocytes were found in P5, P6, P7 and P8 with the biggest value $(\mathrm{p}<0.05)$ obtained in P2. All protocols (P1 to P8) were efficient to concentrate platelets and the lowest value $(3.65 \pm 0.79)$ was found in P1. Regarding TGF- $\beta 1$, the P1 and P8 protocols demonstrated the highest values. According to results, P5 and P8 protocols showed the best results for production of PRP in bovine.
\end{abstract}

INDEX TERMS: PRP, platelet concentrate, cell therapy, growth factor, TGF- $\beta 1$, cattle.

\footnotetext{
${ }^{1}$ Recebido em 31 de março de 2014.

Aceito para publicação em 16 de agosto de 2014 .

Parte da Tese de Doutorado do primeiro autor no Programa de Pós-Graduação em Medicina Veterinária (PPGMV) da Universidade Federal Rural do Rio de Janeiro (UFRRJ). Financiado pela Fundação de Amparo à Pesquisa do Estado do Rio de Janeiro (FAPERJ).

${ }^{2}$ Doutoranda, bolsista Coordenação de Aperfeiçoamento de Pessoal de Nível Superior (CAPES), PPGMV, UFRRJ, Seropédica, RJ 23890-000, Brasil. *Autor para correspondência: marquesapl@ufrrj.br

${ }^{3}$ Departamento de Medicina e Cirurgia Veterinária (DMCV), Instituto de Veterinária, UFRRJ, Seropédica, RJ 23890-000. E-mails: rbotteon@ufrrj.br, pbotteon@ufrrj.br, cahema2@uol.com.br

${ }^{4}$ Doutorando, bolsista CAPES, Curso de Pós-Graduação em Ciências Veterinárias (CPGCV), UFRRJ, Seropédica, RJ 23890-000. E-mail: mathcordeiro@hotmail.com

${ }^{5}$ Doutorandos, bolsistas CAPES, PPGMV, UFRRJ, Seropédica, RJ 23890 000. E-mails: janepaula_7@hotmail.com, bfspindola@yahoo.com.br
}

RESUMO.- Para padronização de uma técnica manual para a obtenção de plasma rico em plaquetas (PRP) autólogo em bovinos com custo reduzido (método manual) e de boa qualidade (capacidade de concentrar plaquetas, alta concentração de fatores de crescimento e contaminação reduzida com leucócitos e eritrócitos), que poderá ser utilizado como um agente modulador da resposta imune de vacas com diferentes enfermidades, $450 \mathrm{ml}$ de sangue total de nove vacas clinicamente saudáveis e com perfil hematológico normal foi coletado em bolsas de sangue CPDA-1 e processado dentro de quatro horas após a coleta. 0 sangue foi separado em alíquotas para avaliar 8 protocolos (P) de centrifugação dupla que variaram quanto a velocidade e o tempo de centrifugação. A contagem de plaquetas, eritrócitos e leucócitos na suspensão obtida (PRP) foi realizada 
pelo método manual em câmara de Neubauer: P5 (400g e $800 \mathrm{~g}$ ambos durante $10 \mathrm{~min}$ ) foi o protocolo com maior número de plaquetas, seguido por P3 (120g e 473g ambos durante $10 \mathrm{~min}$ ), P4 (300g e 640g durante $10 \mathrm{~min}$ cada), P6 (640g durante $10 \mathrm{~min}$ e $640 \mathrm{~g}$ durante $5 \mathrm{~min}$ ), P8 (640g durante $5 \mathrm{~min}$ e $120 \mathrm{~g}$ durante $10 \mathrm{~min})$ e P7 (720g e $720 \mathrm{~g} \mathrm{du}-$ rante $5 \mathrm{~min}$ ) e diferentes $(\mathrm{p}<0,05)$ dos menores valores encontrados em P1 (120g e 240g, ambos por 5 minutos) e P2 (120g e $473 \mathrm{~g}$ ambos por $5 \mathrm{~min}$ ). Em relação aos eritrócitos, P8, P7, P6, P5 e P4 apresentaram menores concentrações e maiores valores $(p<0,05)$ foram observados em P3 e P2. Menores quantidades de leucócitos foram observadas em P5 , P6, P8 e P7 com o maior valor obtido em P2 $(p<0,05)$. Todos os protocolos (P1 a P8) foram eficientes em concentrar plaquetas sendo o valor mais baixo $(3,65 \pm 0,79)$ observado em P1. Em relação aos fatores de crescimento ao se mensurar TGF- 1, os protocolos P1 e P8 evidenciaram valores mais elevados. De acordo com os resultados obtidos os protocolos P5 e P8 apresentaram os melhores resultados para confecção de PRP bovino.

TERMOS DE INDEXAÇÃO: PRP, concentrado de plaquetas, terapia celular, fatores de crescimento, TGF- $\beta 1$, bovinos.

\section{INTRODUÇÃO}

É bem conhecido o papel das plaquetas na hemostasia e coagulação, Contudo, além de atuar no processo de hemostasia, cicatrização e reepitelização de feridas, as plaquetas liberam diversos fatores de crescimento (FC) que estimulam a angiogênese, a proliferação de fibroblastos e citocinas que apresentam propriedades antibacterianas, regenerativas, pró e anti-inflamatórias atuando também no estimulo dos mecanismos de defesa contra infecções (Marx 2004). Estas propriedades conferem ao PRP um grande potencial para acelerar a cicatrização de feridas e emitir sinais celulares estimulando o sistema imune.

Na literatura, o PRP apresenta diversas definições: concentrado de plaquetas (CP), plasma rico em fatores de crescimento, plasma enriquecido em plaquetas ou gel de plaquetas (Whitman, Berry \& Green 1997, Marx et al. 1998). Mais precisamente, o PRP ou plasma enriquecido em plaquetas seria obtido a partir de uma centrifugação leve do sangue total, este plasma quando novamente centrifugado, desta vez em alta rotação, originaria o CP (Brasil 2010) enquanto que o gel de plaquetas seria obtido após a adição de trombina ou gluconato de cálcio ao PRP ou CP resultando na gelificação destes para facilitar a aplicação (Efeoglu et al. 2004). Para melhor entendimento, o termo PRP se refere a um hemocomponente autólogo obtido a partir da centrifugação do sangue total contendo um elevado número de plaquetas e fatores de crescimento em um pequeno volume de plasma (Vendramin et al. 2006).

O PRP pode ser obtido por uma (Macedo 2004, Messora et al. 2009) ou duas centrifugações (Vendramin et al. 2006, Carmona et al. 2007, Barbosa et al. 2008, López et al. 2012), sendo o protocolo de dupla centrifugação a técnica que oferece melhores resultados.

A centrifugação deve ser precisa para separar plaquetas de hemácias, mas objetivando-se obter um plasma com altas concentrações de plaquetas íntegras, pois a fragmen- tação com liberação dos fatores de crescimento reduz a eficácia terapêutica do PRP (Marx 2004).

Algumas metodologias para obtenção de PRP exigiam o uso de grandes equipamentos de autotransfusão (Jameson 2007), com necessidade de grandes volumes de sangue e processamento sob supervisão de um profissional experiente (Vendramin et al. 2006). Alguns equipamentos automáticos menos sofisticados foram propostos, mas com custo elevado (Rossi Júnior \& Souza Filho 2004). Com a finalidade de reduzir os gastos, protocolos utilizando-se centrífugas convencionais foram propostos (Efeoglu et al. 2004).

Atualmente existem três métodos para obtenção de PRP: automático, semiautomático e manual. 0 método manual utilizando uma centrífuga convencional em ambiente laboratorial ou a campo é o mais simples e com menor custo, exigindo rigorosa assepsia (Weibrich et al. 2005), com a possibilidade de se preparar um PRP de boa qualidade e com menor custo (Vendramin et al. 2006), de maior aplicabilidade em medicina veterinária.

A contribuição de terapias celulares na recuperação de tecidos, defesas locais e processos de quimiotaxia está sob interesse crescente e o PRP criou novas perspectivas na terapêutica de diversas doenças. Apesar dos benefícios amplamente estudados na medicina humana e o recente crescimento do seu uso na medicina desportiva equina, até o momento, os trabalhos sobre plaquetas em bovinos envolvem alterações na coagulação (Searcy et al.1990), endotoxemia (Dohmen et al. 2000, Wittek et al. 2004) e celularidade (López et al. 2012), não havendo o interesse pelo uso do PRP de forma terapêutica nesta espécie. Nesse contexto, é proposto por esse estudo padronizar um protocolo para obtenção de PRP bovino autólogo, de fácil execução e de boa qualidade, para posteriormente ser testado em afecções dessa espécie.

\section{MATERIAL E MÉTODOS}

Este estudo foi aprovado pelo comitê de ética sob o número 86/2012 (CEUA - reunião ordinária em 5 de novembro de 2012). Foram utilizadas nove vacas da raça Red Angus da fazenda do Laboratório de Quimioterapia Experimental em Parasitologia Veterinária (LQEPV) da Universidade Federal Rural do Rio de Janeiro (UFRRJ), com idades variando entre 3 e 8 anos (média 5,5), clinicamente saudáveis considerando-se o histórico, a anamnese, o exame físico, a condição corporal entre 3,0 e 3,5 (escala de 1,0 a 5,0) (Wildman et al. 1982, Edmonson et al. 1989), o hemograma (analisador hematológico por impedância ${ }^{6}$ ), a contagem diferencial dos leucócitos (Jain 1993), fibrinogênio e proteínas totais (Coles 1987). Por pertencerem a uma mesma propriedade as condições de manejo e alimentação eram similares.

Para padronização do PRP, $450 \mathrm{ml}$ de sangue de cada animal foi colhido em uma bolsa CPDA- $1^{7}$ simples por punção da veia jugular com agulha 16G após tricotomia e antissepsia. As nove bolsas foram mantidas e transportadas até o Laboratório de Pesquisas Clínicas (LPC), UFRRJ, em uma caixa isotérmica contendo gelo e processadas em até quatro horas. Em cada bolsa foram avaliados oito protocolos (P1 a P8) para a obtenção de PRP, todos de centrifugação dupla variando quanto à velocidade e tempo de centrifugação como demonstrado no Quadro 1.

Para cada protocolo testado foram utilizados $30 \mathrm{ml}$ de sangue acondicionados assepticamente em dois tubos Falcon estéreis de 
Quadro 1. Protocolos de dupla centrifugação utilizados para padronização do PRP autólogo bovino

\begin{tabular}{|c|c|c|c|c|c|}
\hline \multirow[t]{2}{*}{ Protocolo } & \multicolumn{2}{|c|}{ 1ª Centrifugação } & \multicolumn{2}{|c|}{ 2ª Centrifugação } & \multirow[t]{2}{*}{ Referências } \\
\hline & Velocidade & $\begin{array}{l}\text { Tempo } \\
\text { (min.) }\end{array}$ & Velocidade & $\begin{array}{l}\text { Tempo } \\
\text { (min.) }\end{array}$ & \\
\hline P1 & $120 \mathrm{~g}$ & 5 & $240 \mathrm{~g}$ & 5 & Carmona et al. 2007 \\
\hline P2 & $120 \mathrm{~g}$ & 5 & $473 \mathrm{~g}$ & 5 & Maia et al. 2009 \\
\hline P3 & $120 \mathrm{~g}$ & 10 & $473 g$ & 10 & $\begin{array}{l}\text { Maia et al. } 2009 \\
\text { modificado }\end{array}$ \\
\hline $\mathrm{P} 4$ & $300 \mathrm{~g}$ & 10 & $640 \mathrm{~g}$ & 10 & $\begin{array}{l}\text { Vendramin et al. } \\
2006\end{array}$ \\
\hline P5 & $400 \mathrm{~g}$ & 10 & $800 \mathrm{~g}$ & 10 & $\begin{array}{l}\text { Vendramin et al. } \\
2009\end{array}$ \\
\hline P6 & $640 \mathrm{~g}$ & 10 & $640 \mathrm{~g}$ & 5 & * \\
\hline P7 & $720 \mathrm{~g}$ & 5 & $720 \mathrm{~g}$ & 5 & López et al. 2012 \\
\hline P8 & $640 \mathrm{~g}$ & 5 & $120 \mathrm{~g}$ & 10 & * \\
\hline
\end{tabular}

Nota: Carmona et al. 2007 e Maia et al. 2009 confeccionaram PRP a partir de plasma de equinos; Vendramin et al. 2006 e Vendramin et al. 2009 em plasma de humanos e López et al. 2012 avaliaram um protocolo de PRP em plasma de bovinos. * P6 e P8 foram criados aleatoriamente durante o experimento.

$15 \mathrm{ml}$ que foram centrifugados ${ }^{8}$ para separar o plasma da zona de névoa (capa leucocitária) e dos eritrócitos. 0 plasma sobrenadante de ambos os tubos foi arbitrariamente dividido em duas frações, fração plasmática superior (FPS) e fração plasmática inferior (FPI). A FPI considerada como sendo $50 \%$ do plasma mais próximo à capa leucocitária foi mantida e a FPS (50\% da fração plasmática imediatamente superior a PFI) foi descartada. A FPI foi transferida para um terceiro tubo Falcon com pipeta Pasteur e novamente centrifugada, conforme velocidade e tempo estabelecido em cada protocolo. Após a segunda centrifugação, o plasma sobrenadante $(75 \%$ considerado pobre em plaquetas - PPP) foi descartado sendo conservado apenas $25 \%$ da fração inferior considerado PRP (Fig.1).

De cada amostra de PRP obtida foram feitas as contagens de plaquetas, eritrócitos e leucócitos pelo método manual em câmara de Neubauer (Jain 1993). As concentrações de plaquetas, eritrócitos e leucócitos foram determinadas pela porcentagem das variáveis em relação ao sangue total. A concentração do fator de crescimento TGF- $\beta 1$ foi mensurada por kit comercial de ELISA sanduíche ${ }^{9}$ com absorbância de $450 \mathrm{~nm}$, utilizado na determinação quantitativa de TGF- $\beta 1$ em cultura celular, plasma e soro de humano, rato e bovino. Nas etapas de incubação com agitação de placa e leitura em nm foi utilizado um aparelho multiskan ${ }^{10}$. 0 coeficiente de correlação da curva foi 0,9996 e os CV(\%) intra e inter ensaio foram 27,86 e 27,77 , respectivamente. Os dados estão apresentados como média \pm desvio padrão. Os resultados foram analisados por análise de variância (ANOVA) e foi feita a comparação múltipla entre as médias das concentrações encontradas pelo teste de Duncan com $95 \%$ de probabilidade $(\mathrm{p}<0,05)$. A correlação de Pearson foi usada para testar a relação entre a contagem de plaquetas e TGF- $\beta 1$, plaquetas e leucócitos e leucócitos em relação ao TGF- $\beta 1$. As análises foram realizadas usando o programa Prism versão 6.0 para Windows (GraphPad Software, Califórnia, EUA).

\footnotetext{
${ }^{6}$ pocH-100iV Diff, Sysmex.

${ }^{7} 63 \mathrm{ml}$ de solução CPDA-1 (2900mg de dextrose anidra; 2630mg de citrato de sódio, $300 \mathrm{mg}$ de ácido cítrico anidro, $27,5 \mathrm{mg}$ de adenina e $222 \mathrm{mg}$ de fosfato de sódio monobásico), JP Indústria Farmacêutica S.A., lote no 021412 .

${ }^{8}$ Centrífuga clínica para rotina laboratorial, Centribio, Modelo: 80-2B$-15 \mathrm{ML}$.

${ }^{9}$ Enzo Life Science, ADI-900-155.

${ }^{10}$ Multiskan Go,ThermoScientific.
}

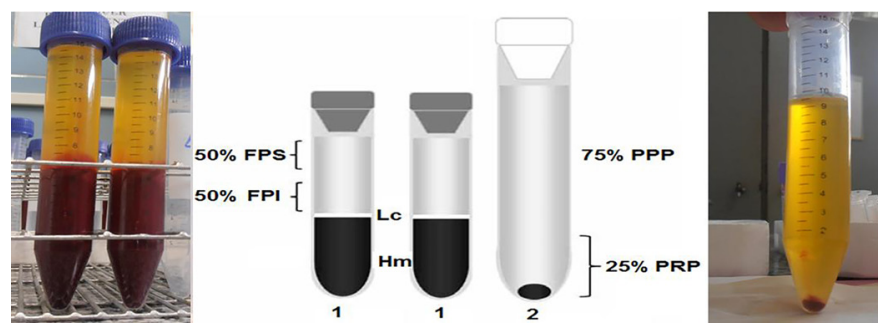

Fig.1. Esquema em preto e branco ao centro: os tubos 1 representam a primeira fração de plasma (FPS e FPI) obtida durante a 1a centrifugação. 0 tubo 2 representa as frações de PRP e PPP obtidas após centrifugação das FPIs dos tubos 1. Figura à esquerda: tubos com a primeira fração do plasma. Figura à direita: PRP e PPP.

FPS = fração plasmática superior; FPI = fração plasmática inferior; Lc = Capa leucocitária; $\mathrm{Hm}$ = Eritrócitos; $\mathrm{PPP}=$ plasma pobre em plaquetas; $\mathrm{PRP}=$ plasma rico em plaquetas (Adaptado de López et al. 2012).

\section{RESULTADOS}

No Quadro 2 são apresentados os resumos dos dados de algumas das variáveis (plaquetas, eritrócitos e leucócitos) no sangue total e em cada protocolo avaliado. Na Figura 2 é possível observar que em todos os protocolos de obtenção de PRP avaliados o número de plaquetas aumentou $(\mathrm{p}<0,05)$ em relação ao sangue total. No Quadro 3 estão discriminados os resultados dessas variáveis (\% em relação ao sangue total) de cada protocolo e no Quadro 4 as concentrações de TGF $\beta-1$.

A média total nos oito protocolos foi de 3.049 .527 \pm 1.225 .201 plaquetas $/ \mu \mathrm{L}$ o que corresponde a 650,70 $\pm 295,48 \%$ mais plaquetas no PRP em relação ao sangue total. A maior concentração de plaquetas foi obtida no P5, $890,53 \pm 277,14 \%$ a mais que no sangue total, seguido ( $p>0,05)$ por P3, P4, P6 e P8, estes 4 últimos com valores semelhantes a P7 $(p>0,05)$ e diferentes $(p<0,05)$ dos menores valores encontrados em P1 e P2. Em relação aos eritrócitos, P8, P7, P6, P5 e P4 apresentaram menores concentrações $(p>0,05)$ sendo as maiores concentrações observadas em P3 e P2 $(p<0,05)$. Os protocolos que apresentaram menores quantidades de leucócitos foram P5 , P6, P8 e P7 $(p>0,05)$ e o maior valor $(p<0,05)$ foi obtido em P2.

P1 e P8 foram os protocolos que se destacaram pela maior concentração de TGF- $\beta 1$, embora o P1 tenha apresentado pouca quantidade de plaquetas e grande quantidade de leucócitos e eritrócitos. 0 menor valor encontrado $(\mathrm{p}<0,05)$ foi no P5, mesmo este tendo papel de destaque na concentração de plaquetas. A média de TGF- $\beta 1$ nos oito protocolos foi de $2.227,39 \pm 618,55 \mathrm{pg} / \mathrm{ml}$.

Entre os protocolos que resultaram em maior concentração de plaquetas apenas o P5 diferiu $(\mathrm{p}<0,05)$ dos demais em relação aos níveis de TGF- $\beta 1$. Houve correlação negativa moderada entre plaquetas e TGF- $\beta 1(\rho=-0,48)$ e entre plaquetas e leucócitos $(\rho=-0,69)$ e, correlação positiva fraca entre leucócitos e TGF- $\beta 1(\rho=0,26)$.

\section{DISCUSSÃO}

Conforme Barbosa et al. (2008) que avaliaram o efeito do PRP em falhas ósseas de cães, a presença de trombocito- 
Quadro 2. Resumo dos dados das variáveis (plaquetas, eritrócitos e leucócitos) no sangue total e em cada protocolo avaliado

\begin{tabular}{|c|c|c|c|c|c|c|c|c|c|}
\hline & & $\mathrm{P} 1$ & P2 & P3 & $\mathrm{P} 4$ & P5 & P6 & P7 & P8 \\
\hline & $\begin{array}{c}\text { Sangue total } \\
\times 10^{3} / \mu \mathrm{l}\end{array}$ & & & & $\begin{array}{c}\text { Plaquetas } \\
\mathrm{x} 10^{3} / \mu \mathrm{l}\end{array}$ & & & & \\
\hline Médias & 494,56 & 1750,00 & 1969,33 & 3422,22 & 3822,00 & 4129,78 & 3292,67 & 2768,00 & 3242,22 \\
\hline DP & 124,38 & 286,01 & 872,07 & 1590,03 & 952,85 & 755,98 & 956,41 & 893,32 & 1099,72 \\
\hline Mínimo & 357 & 1360 & 1030 & 1764 & 2740 & 2986 & 2420 & 1626 & 1790 \\
\hline \multirow[t]{2}{*}{ Máximo } & 751 & 2170 & 3780 & 7190 & 5686 & 5260 & 4940 & 4390 & 5510 \\
\hline & $\mathrm{x} 10^{6} / \mu \mathrm{l}$ & & & & $\begin{array}{c}\text { Eritrócitos } \\
\qquad / \mu \mathrm{l}\end{array}$ & & & & \\
\hline Médias & 6,02 & 1122,22 & 1484,44 & 1800,00 & 962,22 & 820,00 & 780,00 & 753,33 & 648,89 \\
\hline DP & 1,22 & 939,23 & 360,80 & 975,45 & 444,23 & 496,99 & 283,02 & 454,86 & 302,67 \\
\hline Mínimo & 5,59 & 420 & 780 & 440 & 440 & 260 & 460 & 280 & 260 \\
\hline \multirow[t]{2}{*}{ Máximo } & 9,03 & 3160 & 1860 & 3380 & 1780 & 1940 & 1400 & 1460 & 1180 \\
\hline & $\mathrm{x} 10^{3} / \mu \mathrm{l}$ & & & & $\begin{array}{l}\text { Leucócitos } \\
\mathrm{x} 10^{3} / \mu \mathrm{l}\end{array}$ & & & & \\
\hline Médias & 8677,78 & 1406,11 & 1918,33 & 1261,67 & 1491,67 & 637,78 & 768,33 & 1027,22 & 731,67 \\
\hline DP & 2775,24 & 266,74 & 212,53 & 562,56 & 528,73 & 178,45 & 295,28 & 403,28 & 184,54 \\
\hline Mínimo & 4200 & 1020 & 1640 & 220 & 540 & 260 & 370 & 420 & 485 \\
\hline Máximo & 13700 & 1810 & 2210 & 1890 & 2325 & 840 & 1115 & 1590 & 960 \\
\hline
\end{tabular}

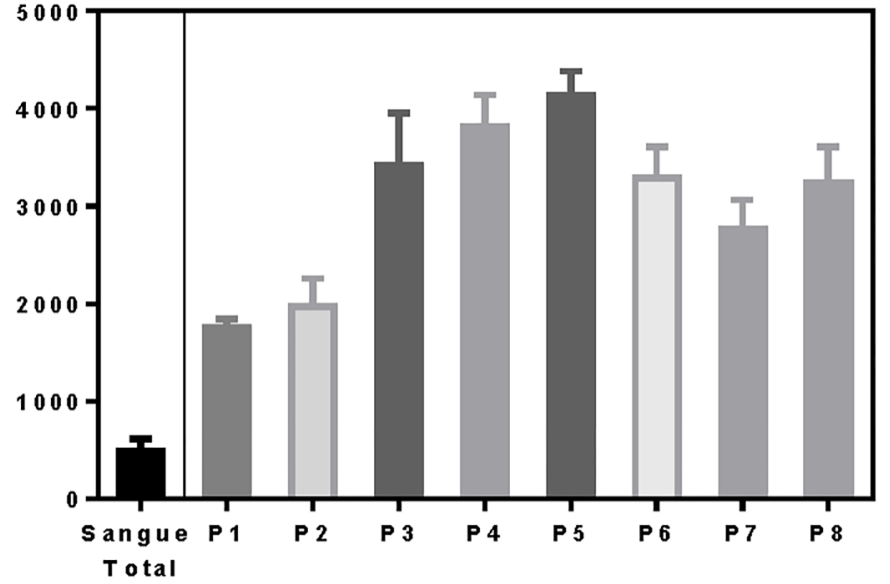

Fig.2. Concentração de plaquetas nos diferentes protocolos para obtenção de PRP avaliados em relação ao sangue total.

penia é um fator limitante na qualidade do PRP sendo o resultado final dependente da contagem inicial das plaquetas no sangue total, desta forma somente animais hígidos e com parâmetros hematológicos normais, especialmente plaquetas foram utilizados nos testes.

A obtenção do PRP pelo método manual, baseado na velocidade e tempo de centrifugação exige a definição do melhor protocolo a ser utilizado. Fatores como anticoagulante, sistema de coleta, quantidade de sangue, treinamento pessoal, bem como o método de contagem das plaquetas (Efeoglu et al. 2004, Jameson 2007) interferem na escolha do método. Como protocolos de apenas uma centrifugação resultam em baixa concentração total de plaquetas (Macedo 2004) neste estudo foram selecionados apenas protocolos de dupla centrifugação.

Diversos protocolos de dupla centrifugação em centrífugas convencionais para diversas espécies têm sido propostos, desta forma a escolha dos protocolos se baseou nos volumes de hemácias de equinos e bovinos (37-59 fl e $36-50 \mathrm{fl}$, respectivamente) e volume de plaquetas de equinos, bovinos e humanos (5,6-8,3 fl, 4,6-8,5 fl e 7,0-10,0 fl, respectivamente) (Ciriades 2008, Weiss \& Wardrop 2010).
Não foram avaliadas centrifugações maiores que $2300 \mathrm{~g}$, pois Adler \& Kent (2002) haviam relatado que a velocidade de centrifugação excessiva pode danificar as plaquetas em humanos e resultar em um PRP de má qualidade. Posteriormente em cães, Ferraz et al. (2007) demonstraram que alta velocidade na segunda centrifugação concentrava maior quantidade de plaquetas, mas estas se encontravam morfologicamente alteradas, interferindo na qualidade do produto.

A média do total de plaquetas nos oito protocolos foi superior às médias descritas por Carmona et al. (2007) (250.000 plaquetas/ $\mu l$ ) utilizando método manual, por Carter et al. (2003) (490.000 plaquetas/ $\mu$ ) utilizando o método automático e por Sutter et al. (2004) (855.000 plaquetas/ $\mu$ l) utilizando o método semiautomático em equinos. 0 valor encontrado neste estudo permite a classificação dos oito protocolos testados como de boa qualidade. De acordo com Marx et al. (1998) o que caracteriza a "boa qualidade" em humanos é uma concentração superior a 1.000.000 plaquetas/ $\mu \mathrm{l}$ ou segundo Whitlow et al. (2008), valores de três a cinco vezes superiores a quantidade de plaquetas presente no sangue total.

A média de plaquetas no P1 e no P2 foi semelhante ao observado por Carmona et al. (2007) e Maia et al. (2009) respectivamente, quando estes trabalharam com equinos, mas quando se compara as médias obtidas em humanos no P4 com resultados de Vendramin (2006) e no P5 com os dados obtidos por Vendramin et al. (2009) associados ao P7 com a avaliação de López et al. (2012) em bovinos, observa-se que as médias obtidas em nosso estudo foram superiores as descritas por estes autores utilizando mesmo protocolo de centrifugação, porém com diferentes volumes de sangue.

Sabendo-se que o tamanho e o peso das plaquetas e leucócitos determinam o protocolo mais efetivo para concentrar plaquetas em cada espécie (López et al. 2012) e que o processo de centrifugação e separação do plasma deve ser executado com muita precisão para separar as plaquetas dos eritrócitos e leucócitos que são considerados contami- 
Quadro 3. Resumo dos dados das concentrações de plaquetas, eritrócitos e leucócitos de cada protocolo avaliado (\% de cada tipo celular em relação ao sangue total)

\begin{tabular}{|c|c|c|c|c|c|c|c|c|}
\hline & P1 & P2 & P3 & P4 & P5 & P6 & P7 & P8 \\
\hline & \multicolumn{8}{|c|}{ Plaquetas* } \\
\hline Médias & $365,24^{c}$ & $406,09^{c}$ & $711,14^{\mathrm{ab}}$ & $813,01^{\mathrm{ab}}$ & $890,53^{a}$ & $708,65^{\mathrm{ab}}$ & $608,71^{\mathrm{bc}}$ & $702,23^{\mathrm{ab}}$ \\
\hline DP & 79,50 & 160,62 & 262,53 & 268,41 & 277,14 & 309,61 & 271,36 & 298,80 \\
\hline Mínimo & 283,62 & 213,69 & 234,89 & 446,07 & 397,60 & 376,95 & 255,45 & 314,25 \\
\hline \multirow[t]{2}{*}{ Máximo } & 546,22 & 687,38 & 1119,94 & 1328,50 & 1210,08 & 1383,75 & 971,24 & 1219,03 \\
\hline & \multicolumn{8}{|c|}{ Eritrócitos* } \\
\hline Médias & $0,0176^{\mathrm{bc}}$ & $0,0246^{\mathrm{ab}}$ & $0,0291^{\mathrm{a}}$ & $0,0164^{\mathrm{bc}}$ & $0,0130^{c}$ & $0,0129^{c}$ & $0,0127^{c}$ & $0,0110^{c}$ \\
\hline DP & 0,0116 & 0,0057 & 0,0146 & 0,0088 & 0,0061 & 0,0040 & 0,0079 & 0,0057 \\
\hline Mínimo & 0,0056 & 0,0149 & 0,0078 & 0,0065 & 0,0050 & 0,0085 & 0,0035 & 0,0044 \\
\hline \multirow[t]{2}{*}{ Máximo } & 0,0397 & 0,0352 & 0,0505 & 0,0360 & 0,0257 & 0,0194 & 0,0275 & 0,0191 \\
\hline & \multicolumn{8}{|c|}{ Leucócitos* } \\
\hline Médias & $17,93^{\mathrm{b}}$ & $24,40^{\mathrm{a}}$ & $13,80^{\mathrm{bc}}$ & $17,42^{\mathrm{b}}$ & $7,67^{\mathrm{d}}$ & $8,95^{\mathrm{cd}}$ & $11,90^{\text {cd }}$ & $9,26^{\mathrm{cd}}$ \\
\hline DP & 6,65 & 9,78 & 3,93 & 4,89 & 2,68 & 2,53 & 3,28 & 3,79 \\
\hline Mínimo & 7,45 & 16,13 & 5,24 & 10,63 & 5,91 & 4,64 & 8,00 & 5,10 \\
\hline Máximo & 29,52 & 48,57 & 17,03 & 26,55 & 14,48 & 11,75 & 16,74 & 16,55 \\
\hline
\end{tabular}

* \% em relação ao sangue total. Para cada tipo celular avaliado, as médias seguidas pela mesma letra não diferem estatisticamente entre si.

Quadro 4. Concentração de TGF- $\beta 1$ (pg/ml) nos protocolos (P1 a P8) utilizados para obtenção de PRP autólogo bovino

\begin{tabular}{lcccccccc}
\hline & P1 & P2 & P3 & P4 & P5 & P6 & P7 & P8 \\
\hline Médias & $2432,95^{\text {a }}$ & $2174,27^{\text {ab }}$ & $2157,30^{\text {ab }}$ & $2324,43^{\text {ab }}$ & $1744,21^{\text {b }}$ & $2288,32^{\text {ab }}$ & $2261,28^{\text {ab }}$ & $2422,67^{\text {a }}$ \\
DP & 555,67 & 783,87 & 507,05 & 629,35 & 766,13 & 582,82 & 518,66 & 509,97 \\
Mínimo & 1100,08 & 434,46 & 1308,00 & 1061,54 & 27,00 & 1250,54 & 1218,92 & 1332,08 \\
Máximo & 2811,54 & 2814,00 & 2891,62 & 2885,38 & 2446,08 & 2773,15 & 2937,62 & 2912,46
\end{tabular}

As médias seguidas pela mesma letra não diferem estatisticamente entre si.

nantes das amostras de PRP (Marx 2004). 0 fato de P2 e P3 apresentarem mais eritrócitos e P2 o maior índice de leucócitos, pode estar relacionado à menor força $(\mathrm{g})$ associada ao tempo de centrifugação destes protocolos em relação aos outros.

A presença de leucócitos no PRP é controversa. Alguns autores alegam que a presença de células brancas confere resistência natural aos processos infecciosos e/ou alérgicos, melhorando as expectativas dos tratamentos com esse recurso em humanos (Ruggeri 1997, Marx \& Garg 1999). Carmona et al. (2007) em equinos recomenda minimizar o número de leucócitos no PRP quando se deseja utilizá-lo em articulações e, McCarrel \& Fortier (2009) sugerem uma relação entre leucócitos no PRP com o aumento do catabolismo e diminuição da síntese de matriz extracelular nos tecidos humanos, o que pode interferir na ação regenerativa de tecidos e não no PRP como modulador de resposta imune já que parece haver uma correlação positiva entre leucócitos e o fator de necrose tumoral e a IL-1 (Mccarrel \& Fortier 2009).

A média de TGF- $\beta 1$ dos protocolos testados foi inferior ao descrito por Carter et al. (2003) (7.480pg/ml), Sutter et al. (2004) (23.600pg/ml) e Carmona et al. (2007) (12.515pg/ $\mathrm{ml}$ ) ao pesquisarem o fator de crescimento em equinos. 0 P1 apresentando grande concentração de TGF- $\beta 1$ e leucócitos e pouca quantidade de plaquetas evidenciou como proposto por Weibrich et al. (2003) para humanos, que além das plaquetas diversas células (leucócitos por exemplo), tem a capacidade de liberar fatores de crescimento.
0 aumento da velocidade na segunda centrifugação como feito por Aghallo et al. (2002), Scarso Filho (2002) e Ferraz et al. (2007) em coelhos, humanos e cães, respectivamente, baseou-se no fato de que uma segunda rotação, de maior intensidade, permitiria separar melhor a fração do plasma pobre em plaquetas, que corresponde à parte superior, da parte inferior, que representa o PRP (Barroso et al. 2007). Os protocolos $\mathrm{P} 6$ e P8, criados com segunda centrifugação menor em tempo (P6) e em tempo e intensidade (P8) do que a primeira, nesse método manual, apresentaram boa capacidade de concentração de plaquetas associada a altos valores de TGF- $\beta 1$. Os resultados de P8 evidenciaram que, independente do protocolo, a meta é aumentar a contagem plaquetária em uma concentração bem acima da encontrada no sangue total, preservando a estrutura e a função das plaquetas, como indicado por López et al. (2012), onde afirmam que se as plaquetas se romperem ou se ativarem antecipadamente liberando os fatores de crescimento, a ação terapêutica do PRP será prejudicada e isto ocorre em velocidades (força g) altas (Ferraz et al. 2007).

Vendruscolo et al. (2012) em equinos não observaram diferença entre protocolos que mais concentraram plaquetas em relação aos níveis de TGF- $\beta 1$ o que não ocorreu em nosso estudo, ficando o P5 com grandes quantidades de plaquetas e reduzida concentração de TGF $\beta-1$ quando comparado aos protocolos que mais concentraram plaquetas. A correlação negativa moderada entre plaquetas e TGF- $\beta 1$ e entre plaquetas e leucócitos e uma correlação positiva entre leucócitos e TGF- $\beta 1$ são resultados diferen- 
tes dos encontrados por López et al. (2012) que evidenciaram correlações positivas entre leucócitos e plaquetas, mas corroboram com Weibrich et al. (2003) quando estes evidenciaram que diversas células são capazes de produzir fatores de crescimentos.

\section{CONCLUSÃO}

Os protocolos de centrifugação $400 \mathrm{~g}$ e $800 \mathrm{~g}$ ambas durante 10 min (P5) e 640g durante 5 min e $120 \mathrm{~g}$ durante $10 \mathrm{~min}$ (P8) apresentaram bons resultados e podem ser utilizados em bovinos por apresentarem altas concentrações de plaquetas e elevados valores de TGF- $\beta 1$.

\section{REFERÊNCIAS}

Adler S.C. \& Kent K.J. 2002. Enhancing wound healing with growth factors. Facial Plast. Surg. Clin. North Am. 10:129-146.

Aghallo T.L., Moy P.K. \& Freymiller E.G. 2002. Investigation of platelet-rich plasma in rabbit cranial defects: a pilotstudy. J. Oral Maxillofac. Surg. 60:1176-1181.

Barbosa A.L.T., Del Carlo R.J., Gomes H.C., Oliveira A.C., Monteiro B.S. \& Del Carlo B.N. 2008. Plasma rico em plaquetas para reparação de falhas ósseas em cães. Ciência Rural 38:1335-1340.

Barroso C.S.T., Benito J.C. \& Puig A.G. 2007. Calidad del plasma rico en plaquetas: estúdio de la activación plaquetaria. Revta Esp. Cir. Oral Maxilofac. 29:240-248.

Brasil. 2010. Guia para o uso de hemocomponentes. Editora do Ministério da Saúde, Brasília. 140p.

Carmona J.U., Argüelles D., Climent F. \& Prades M. 2007. Autologous platelet concentrates as a treatment of horses with osteoarthiritis: a preliminary pilot clinical study. J. Equine Vet. Sci. 27(4):167-170.

Carter C.A., Jollya D.G., Worden C.E., Hendrena D.G. \& Kane C.J.M. 2003. Platelet rich plasma gel promotes differentiation and regeneration during equine wound healing. Exp. Mol. Pathol. 74(3):244-255.

Ciriades P.G.J. 2008. Manual de Patologia Clínica. Atheneu, São Paulo. 1070p.

Coles E.H. 1987. Veterinary Clinical Pathology. $4^{\text {th }}$ ed. Lea and Febiger, Philadelphia. 421p.

Dohmen M.J.W., Joop K., Sturk A., Bols P.E.J. \& Lohuis J.A.C.M. 2000. Relationship between intra-uterine bacterial contamination, endotoxin levels and the development of endometritis in postpartum cows with dystocia or retained placenta. Theriog. 54:1019-1032.

Edmonson A.J., Lean I.J., Weaver L.D., Farver T. \& Webster G. 1989. A body condition scoring chat for Holstein dairy cows. J. Dairy Sci. 72:68-78.

Efeoglu C., Akcay Y.D. \& Erturk S. 2004. A modified method for preparing platelet-rich plasma: an experimental study. J. Oral Maxillofacial Surg. 62(11):1403-1407.

Ferraz V.C.M., Ferrigno C.R.A. \& Schmaedecke A. 2007. Platelet concentration of platelet rich plasma from dogs, obtained through three centrifugation speeds. Braz. J. Vet. Res. Anim. Sci. 44:435-440.

Jain N.C. 1993. Veterinary Hematology. Lea and Febger, Philadelphia. $417 \mathrm{p}$.

Jameson C.A. 2007. Autologous platelet concentrate for the production of platelet gel. Lab. Med. 38:39-42.

López C., Giraldo C.E. \& Carmona J.U. 2012. Evaluación de un método de doble centrifugación en tubo para concentrar plaquetas bovinas: estudio celular. Arch. Med. Vet. 44:109-115.

Macedo A.P. 2004. Plasma rico em plaquetas: uma análise quantitativa e qualitativa de dois protocolos de obtenção. Dissertação de Mestrado em Odontologia, Faculdade de Odontologia, Universidade Federal de Santa Catarina, Florianópolis, SC. 64p.

Maia L., Souza M.V., Alves G.E.S., Ribeiro Júnior J.I., Oliveira A.C., Silva Y.F.R.S. \& Zandim B.M. 2009. Plasma rico em plaquetas no tratamento de tendinite induzida em equinos: avaliação ultra-sonográfica. Pesq. Vet. Bras. 29(3):241-245.

Marx R.E. 2004. Platelet-rich plasm: evidence to support its use. J. Oral Maxillofac. Surg. 62:489-496.

Marx R.E., Carlson E.R., Eichstaedt R.M., Schimmele S.R., Strauss J.E. \& Georgeff K.R. 1998. Platelet-rich plasm: growth factor enhancement for bone grafts. Oral Surg. Oral Med. Oral Pathol. 85(6):638-646.

Marx R.E. \& Garg A.K. 1999. Bone graft physiology with use of platelet-rich plasma and hiperbaric oxygen, p. 183-189. In: Jensen Ole T. (Ed.), The Sinus Bone Graft. Quintessense Publisher, Colorado.

McCarrel T. \& Fortier L.A. 2009. Temporal growth factor release from platelet-rich plasma, thehalose lyophilized platelets, and bone marrow aspirate and their effect on tendon and ligament gene expression. J. Orthop. Res. 27:1033-1042.

Messora M.E., Nagata M.J.H., Melo L.G.N., Furlaneto F.A.C., Deliberador T.M., Garcia V.G. \& Bosco A.F. 2009. Análise de um protocolo de única centrifugação para o preparo do plasma rico em plaquetas (PRP) - estudo em coelhos. Revta Sul-Bras. Odontol. 6(2):135-141.

Rossi Júnior R. \& Souza Filho M.A.P. 2004. Obtenção de trombina autógena: proposta de um protocolo simplificado e de fácil reprodução clínica. Revta Paul. Odontol. 26:4-9.

Ruggeri Z.M. 1997. Mechanisms initialing platelet thrombus formation. Thromb. Haemost. 78(1):611-616.

Scarso Filho J. 2002. Avaliação do plasma rico em plaquetas na proliferação celular. Estudo in vitro. Tese de Doutorado em Odontologia, Faculdade de Odontologia, Universidade Federal de Santa Catarina, Florianópolis, SC. 75p.

Searcy G.P., Sheridan D. \& Dobson K.A. 1990. Preliminary studies of a platelet function disorder in Simmental cattle. Can. J. Vet. Res. 54:394-396.

Sutter W.W., Kaneps A.J. \& Bertone A.L. 2004. Comparison of hematologic values and transforming growth factor-beta and insulin-like growth factor concentrations in platelet concentrates obtained by use of buffy coat and apheresis methods from equine blood. Am. J. Vet. Res. 65(7):924-930.

Vendramin F.S., Franco D., Nogueira C.M., Pereira M.S. \& Franco T.R. 2006. Plasma rico em plaquetas e fatores de crescimento: técnica de obtenção e utilização em cirurgia plástica. Revta. Col. Bras. Cir. 33(1):24-28.

Vendramin F.S., Franco D. \& Franco T.R. 2009. Método de obtenção do gel de plasma rico em plaquetas autólogo. Revta Bras. Cir. Plást. 24(2):212218.

Vendruscolo C.P., Carvalho A.M., Moraes L.F., Maia L., Queiroz D.L., Watanabe M.J., Yamada A.L.M. \& Alves A.L.G. 2012. Avaliação da eficácia de diferentes protocolos de preparo do plasma rico em plaquetas para uso em medicina equina. Pesq. Vet. Bras. 32(2):106-110.

Weibrich G., Kleis W.K., Hafner G., Hitzler W.E. \& Wagner W. 2003. Comparison of platelet, leukocyte, and growth factor levels in point-of-care platelet-enriched plasma, prepared using a modified Curasan kit, with preparations received from a local blood bank. Clin. Oral Implants Res. 14(3):357-362.

Weibrich G., Wilfried K.G., Kleis W.K., Hitzler W.E. \& Hafner G. 2005. Comparison of the platelet concentrate collection system with the plasma rich in growth factors kit to produce platelet rich plasma: a technical report. Int. J. Oral Maxillofacial Implants 29:118-123.

Weiss D.J. \& Wardrop K.J. 2010. Schalm's Veterinary Hematology. $6^{\text {th }}$ ed. Blackwell Publishing, Iowa. 1232p.

Whitlow J., Shackelford A.G., Sievert A.N. \& Sistino J. 2008. Barriers to the acceptance and use of autologous platelet gel. Perfusion 23:283-289.

Whitman D.H., Berry R.L. \& Green D.M. 1997. Platelet gel: an autologous alternative to fibrin glue with applications in oral and maxillofacial surgery. J. Oral Maxillofacial Surg. 55:1294-1299.

Wildman E.E., Jones G.M., Wagner P.E., Boman R.L., Troutt Jr H.F. \& Lesch T.N. 1982. A dairy cow body condition scoring system and its relationship to selected production characteristics. J. Dairy Sci. 65:495-501.

Wittek T., Fürll M. \& Constable P.D. 2004. Prevalence of endotoxemia in healthy postparturient dairy cows and cows with abomasal volvulus or left displaced abomasum. J. Vet. Intern. Med. 18:574-580. 